\title{
Taxi Tipping in New York City (2014-2017): Reciprocity in Hailed vs. Dispatched Cab Fares
}

\author{
Amber Raymond, B. S. W., \& Kenneth Cramer, Ph. D. \\ University of Windsor
}

\begin{abstract}
The present study evaluated the extent to which reciprocity (equity) theory could explain differential levels of tipping in New York taxi fares. From 2014 to 2017, the database recorded 73 million cab fares; however, only credit transactions (i.e., recording patrons' tips) were included (28 million fares). Based on a reciprocity hypothesis, patrons in cabs hailed randomly off the street were expected to tip more compared to patrons who arranged travel at a dispatch centre. An analysis of covariance for each of the four years supported this, wherein patrons in hailed cabs tipped twice the percentage (14\%) than patrons in dispatched cabs $(7 \%)$; these results were confirmed using equivalent procedures that assumed neither normality nor variance homogeneity. Several limitations are discussed, as are directions for future research.
\end{abstract}

Keywords: reciprocity, tipping, equity, genuine intention, taxi

La présente étude a tenté d'évaluer dans quelle mesure la théorie de la réciprocité pourrait expliquer les différences de pourboire à la suite des courses de taxis à New York. La base de données incluait exclusivement les transactions par crédit (c.-à-d., 28 millions de courses sur 73 millions) de 2014 à 2017. À partir d'une hypothèse de réciprocité, nous prédisions que les chauffeurs de taxis hélés au hasard reçoivent plus de pourboire que ceux ayant été dépêchés par un centre de répartition. Une analyse de covariance pour chacune des quatre années a permis de déterminer que les clients des taxis hélés ont donné des pouboires deux fois plus importants (14\%) que les clients des taxis expédiés $(7 \%)$. Ces résultats ont été confirmés en utilisant des procédures équivalentes qui ne supposaient ni normalité ni homogénéité de la variance. Plusieurs limites sont abordées, ainsi que les orientations des recherches futures.

Mots-clés : réciprocité, pourboire, équité, véritable intention, taxi

Merriam-Webster (Tip, 2019) defines a tip as "a gift or a sum of money tendered for a service performed or anticipated." The practice of tipping in the service industry is believed to have begun in sixteenth-century England, in coffee shops frequented by higher class individuals. Coffee shop owners would display a brass box labelled "To Insure Promptitude" into which individuals would place a coin at various times throughout their stay (Azar, 2003). The custom of tipping was also prevalent throughout sixteenthcentury Europe in the hotel industry, wherein residents were expected to tip specific amounts to all staff members; not doing so could result in consequences like an injured horse (Azar, 2003). Tipping made its way to the United States in the mid-1800s by way of wealthy Americans gloating of their travels abroad (Segrave, 2009). Today, in much of North America, tipping has become a social norm: "people often [...] feel guilty, unfair and embarrassed if they do not

I would like to express my sincere appreciation to my research supervisor, Dr. Ken Cramer. It was through his persistent guidance that I learned how to navigate research software, thoroughly conduct research and present it clearly and excitingly. Dr. Cramer has encouraged personal growth and sparked a fond love of research and psychology. It was a privilege and honour to work and study under his supervision. Correspondence concerning this article should be addressed to Amber Raymond (raymonda@uwindsor.ca) or Kenneth Cramer (kenneth. cramer@uwindsor.ca). tip" (Azar, 2005, p. 142). Tipping occurs across a wide range of occupations, including hairstylists and beauticians, bartenders and waitstaff, and taxi and delivery drivers. Because several occupations rely on tips to supplement up to $75 \%$ of their income (Payscale, 2019), research on tipping behavior remains worthwhile and relevant. In particular, a broader knowledge of what influences tipping can help develop more effective strategies for increased take-home income in the service industry. Beyond the obvious benefits to service staff, familiarity with the psychology of tipping should prove useful for managers and business owners so as to better satisfy patrons in the provision of optimal customer service. Whereas the majority of research has focused on predicting tips offered to waitstaff, Lynn (2016) found that the taxi industry ranked 5th among 21 occupations for the likelihood of tip, surpassed only by bartenders, hairstylists, food delivery personnel, and waitstaff. Given the spectrum of interpersonal relations and group dynamics that naturally transpire in the course of a taxi fare, the present study evaluated the feasibility of reciprocity theory to predict New York City taxi tips from 20142017. 


\section{RAYMOND \& CRAMER}

\section{Interpersonal Antecedents in Tipping}

The practice of tipping constitutes one of several interpersonal interactions between the consumer and service provider, as dictated by social norms and informal rules. Generally speaking, the price for goods and services is set by the service provider and is often known well before the transaction. Conversely, any tip amount is determined by the consumer and varies based on a host of social, performance, and interpersonal factors. Research on what influences tipping (whether absolutely or as a percentage of the bill) has focused on the possible social, psychological, and strategic motivating factors that prompt individuals to leave a particular size of gratuity (Azar, 2005, 2007, 2010; Lynn, 2016; Lynn \& Latané, 1984).

Studies suggest that the service provider can increase tip amounts by utilizing subtle interpersonal interaction techniques, such that tips are markedly higher when the provider: touches or compliments the patron (Crusco \& Wetzel, 1984; Seiter, 2007; Seiter \& Dutson, 2007), introduces themselves (Garrity \& Degelman, 1990), returns excess change to the patron (Azar, Yosef, \& Bar-Eli, 2015), or includes a candy or "thank you" with the bill (Rind \& Bordia, 1995, 1996; Strohmetz, Rind, Fisher, \& Lynn, 2002). Lynn, Jabbour, and Kim (2012) found that tips were higher with more time spent in the restaurant, but only when the bill was relatively small. They suggested that patrons elected to compensate waitstaff for taking up their time, which compromised service (and tip) opportunities with other customers while they lingered (or loitered). Whereas the above study addressed restaurant service only, we extend this body of research into the taxi industry.

Moreover, Van Vaerenbergh and Holmqvist (2013) evaluated whether being served in one's native language (as opposed to their second language) would influence the decision to tip; indeed, results showed patrons as more willing to tip when served in one's native language-even when visiting outside their country of origin. These data show that people appreciate the effort and accommodations from service personnel, further supporting the notion that tipping is a way of rewarding a service provider for "going the extra distance" (i.e., offering additional service and comfort beyond expectations). Whereas the authors only investigated waitstaff, Van Vaerenbergh and Holmqvist (2013) further employed an unfortunate binary measure of tipping (i.e., "would you tip or not") rather than a more informative continuous measure that we adopted presently.

Beyond the restaurant industry, a recent observational study on tipping taxi drivers sheds valuable light on those factors that predict driver tip (Aydin \& Acun, 2019). Although blind to the purpose of the study, data were collected by drivers trained to observe and record patron gender, fashion, conversation levels, and efforts of patrons to seek status; they further logged both tip amount and distance travelled. With little surprise, results showed that tips increased with greater distances and with more conversation between driver and patron. Additionally, patrons who sought more social status (by wearing more fashionable clothing and choosing to sit in the back seat) similarly offered higher tips. The authors, however, noted one key drawback in their use of observational data, that is, clothing fashion and conversation levels were left at the discretion of the driver, and open arguably to bias. To address these concerns, the present study utilized an electronic database free of observational bias.

\section{Mechanism of Reciprocity in Taxi Tipping}

The above examples may each be explained by the norm of reciprocity, wherein we feel compelled to treat others as they have treated us. Under Hammurabi's Law's, this principle would guide matters of justice (i.e., "an eye for an eye"), but in everyday interactions, reciprocity refers simply to the mutual exchange of favors. As Gouldner (1960, p.162) notes: "social equilibrium could not exist without the reciprocity of service and return service." For the present discussion of tipping, we refer to the definition from Fehr and Gächter (2000, p.159): "Reciprocity means that in response to friendly actions, people are frequently much nicer and much more cooperative than predicted."

A classic study by Regan (1971) should elucidate the construct and its impact on compliance. A participant and confederate were seated together in an aesthetics experiment, specifically judging the quality of artworks. The confederate was instructed secretly to behave toward the participant in either a likeable or unlikeable manner. In one condition, the confederate left the room and returned with two bottles of cola (offering one to the participant). In another condition, the confederate returned with no beverage. The confederate said they were selling raffle tickets to raise money for their sports club (\$0.25 each) and asked if the participant wished to purchase any. Results showed that even when the confederate was perceived as unlikeable, participants who received the free cola felt compelled to purchase more raffle tickets (on average spending \$0.43). With respect to the present study, we review herein a variety of ways by which reciprocity can explain the interpersonal transaction between customer and service provider following a cab ride, including (a) need for equity and (b) repaying someone for their genuine intention to help. 


\section{TAXI TIPPING IN NYC}

Need for Equity. The results of Van Vaerenbergh and Holmqvist (2013) offer initial support for the reciprocity theory (Gilovich, Keltner, Chen, \& Nisbett, 2019). The imbalance created within the individual by "taking without giving" causes one to fell indebted to another, resulting in guilt, which motivates correction. The reciprocity norm was empirically identified in the service industry by Becker, Bradley, and Zantow (2012) using factor analysis of customer tip motives for services provided. In the context of the taxi industry, it is likely that individuals who hail a cab (i.e., waved down haphazardly in the street) would be more grateful than those who specifically dispatch a hired car. This has been referred to as the State-Relief Motive (Cialdini, 1993). In other words, the cab driver stopping by chance may have rescued the passenger from any number of unpleasant circumstances, including excessive delay or fatigue, foul weather, or even a dangerous neighborhood. The norm of reciprocity suggests that, compared to pre-arranged or dispatched cabs, patrons will appreciate and tip hailed drivers more because patrons enter a direct reciprocal relationship with hailed drivers. They however enter a reciprocal relationship with a company (and not the driver) in the case of pre-arranged or dispatched cabs.

In this instance, the tip (especially for hailed fares) is seen as a reciprocal reward based on the patron's gratitude toward the driver. According to research by Fehr and Gächter (2000), reciprocity applies to both long-term and random encounters from service providers unlikely to have future encounters with those same patrons. According to the New York City Taxi and Limousine Commission (2019), there are approximately 13,500 cabs within the greater New York metropolitan area. Therefore, the likelihood of securing the same driver multiple times is minimal, suggesting future service is not likely the reason for leaving a tip. Overall, the reciprocity theory would predict that a hailed cab would generate greater tips from grateful patrons.

Perceived genuine intention. Whereas it is arguable that a patron can be rescued from a negative state or situation by an opportune taxi, it is also conceivable that patrons are grateful for the hailed taxi driver who chose to pull over through a genuine intention to help. As such, the hailed taxi driver who chooses to stop may be perceived as more helpful which thus renders a larger gratuity. Rind and colleagues (Rind \& Bordia, 1995, 1996; Rind \& Strohmetz, 1999; Strohmetz et al., 2002) showed that including a candy or "thank you" increased tip amount by upwards of $17 \%$, and attributed this phenomenon to customers' perceptions of server kindness. That kindness, much like a driver's choice to intercept the pedestrian, would thus compel offering a greater gratuity. The present study argues that patrons recognize the dispatched driver's arrival at the prearranged time and place. Yet they perceive more positively the hailed driver who chooses to stop and help a patron in need (thus garnering a larger tip).

\section{Present Study and Hypothesis}

This exploratory study evaluated the suitability of reciprocity theory to explain differential levels of tip percentage for New York City cab fares from 2014 to 2017. While the present study is unable to pinpoint the precise mechanism within reciprocity theory that yields greater tipping due to a lack of qualitative data, both needs for equity and altruistic intentions remain relevant. Based on prior research (Aydin \& Acun, 2019; Azar et al., 2015; Garrity \& Degelman, 1990; Rind \& Bordia, 1995, 1996; Strohmetz et al., 2002) that found that tips increased in imbalanced (inequitable) situations that included an introduction, excess change, or a candy or "thank you" on the bill, we hypothesized that after accounting for number of passengers and both day and month travelled, patrons who hail their taxi will tip by a greater percentage than patrons who dispatch taxis by prior arrangement. We refer to our study as exploratory to stress its generation of testable hypotheses using a secondary data source.

\section{Method}

We utilized the open-access New York City taxi database (New York City Taxi and Limousine Commission, 2019), which electronically tracks cab fares in the larger metropolitan New York City area. The number of daily fares averaged 56,000 and totalled millions of fares each year. This database represents the bulk of the taxis in New York, though smaller operations (including Uber and Lyft drivers) were not included (a noteworthy limitation we will discuss later). We selected fares from January 2014 to December 2017 inclusive, since they were reasonably complete based on the following measures: Time/Date of fare pickup and drop-off, number of passengers (1 to 9), distance travelled (in miles), travel fare, toll fees, tip amount, and total fare (the sum of the travel fare, the tip and the tolls). For example, data collection prior to 2014 did not specify hailed vs. dispatched fare; in addition, data collection after June 2018 excluded pickup and drop-off coordinates. Our key dependent variable was the ratio of the tip amount to the total fare, what we herein refer to as "tip percentage". The database also recorded the type of trip, that is whether the fares were hailed $(\sim 99 \%)$ or dispatched through a central operator $(\sim 1 \%$; we will discuss this wide disparity later in our discussion). Although patrons could remit payment by either cash or credit, only credit transactions recorded the patron's tip. We presume that in the majority of cases, the tip 


\section{RAYMOND \& CRAMER}

was awarded by a single patron in the event of a multiple-passenger fare. We reviewed the dataset from each year for the presence and distribution of missing data and noted one anomalous year in particular. Whereas random data loss was quite low in each of the years $2015-2017(1.4 \%$ to $1.9 \%)$, it was markedly higher (11.3\%) in 2014. Missing entries in this year were distributed evenly throughout the timeline, and we found no significant relation of missing data to the relevant variables. Having deleted cases with missing values, the final dataset consisted of 28,307,391 taxi fares, broken down by year as follows: 2014 $(5,809,416), 2015(8,710,909), 2016(7,969,326)$, and $2017(5,817,740)$. The division of analysis by year further offered a replicability verification check into the validity of the findings.

\section{Results}

We set the statistical significance to a very conservative level $(\alpha=.001)$ for all analyses (due to the high power and number of observations), and employed Bonferroni corrective measures to prevent any inflation of Type I errors due to multiple testing across the four years. Additionally, we coupled our parametric analysis with a nonparametric equivalent, given some degree of nonnormality in the distribution of tip percentage. Specifically, skewness, "a measure of distribution symmetry" (Field, 2013, p. 884) ranged for hailed cabs from -0.308 to 0.086 but ranged for dispatched cabs from 1.35 to 1.55. All skewness standardizations (i.e., skewness divided by standard error; Field, 2013) yielded z-scores of 30 or more ( $p$ s $<.001$ ), suggesting nonnormality. Similarly, kurtosis, a measure of clustering or bunching of observations in the distribution tails (Field, 2013), ranged for hailed cabs from 2.46 to 6.16 , but from 1.11 to 6.42 for dispatched cabs. All kurtosis standardizations (i.e., kurtosis divided by standard error; Field, 2013) yielded $z$-scores of 1200 or more $(p s<.001)$, suggesting nonnormality. Finally, we selected three variables available in the datasetnumber of passengers, day of the week, and month of the year-to serve as covariates in an effort to reduce unexplained variance. We believed these variables were likely to account for significant variance in tipping given the greater volume of taxi travel Friday to Sunday and during winter months (New York City Taxi and Limousine Commission, 2019). Overall, we employed Trip Type (hailed vs. dispatched cab) as the grouping variable, tip percentage as the dependent variable, and three variance-reducing covariates in an Analysis of Covariance (ANCOVA) in each of the four years to evaluate the reciprocity hypothesis (see Table 1). A comparison of hailed vs. dispatched mean tip percentage by year revealed a consistent pattern wherein tip percentage was twice as high for hailed cabs $(14 \%)$ compared to dispatched cabs $(7 \%)$; this was significant for each of the four years, even with the Bonferroni correction $(p<.001)$. However, we noted that the larger standard deviation (or average spread of scores) occurred in the group with the fewest observations (dispatched fares). This can render a statistical test unacceptably liberal (Tabachnick \& Fidell, 2013); indeed, Levene's test of variance homogeneity confirmed for each of the four years that the variances between the two groups were significantly different $(p s<.005$, after Bonferroni correction).

Whereas ANCOVA may be resistant to modest violations of its derivational assumptions (Field, 2013; Howell, 2010), we elected to take additional precautions by utilizing variance homogeneity corrective procedures (viz., Brown-Forsythe algorithms), which did not assume equivalent variances between conditions. Across each of the four years, results were consistent with the conclusions of the original analysis, wherein drivers in hailed cabs

Table 1

ANCOVA: Tip Percentage for Hailed vs. Dispatched Taxis by Year

\begin{tabular}{|c|c|c|c|c|c|c|c|c|c|c|}
\hline \multirow[b]{2}{*}{ Year } & \multicolumn{3}{|c|}{ Hailed } & \multicolumn{3}{|c|}{ Dispatched } & \multicolumn{4}{|c|}{ ANCOVA* } \\
\hline & $M$ & $S D$ & $n$ & $M$ & $S D$ & $n$ & $F_{H D}$ & $F_{P}$ & $F_{D}$ & $F_{M}$ \\
\hline 2014 & 13.93 & 7.01 & $5.78 \mathrm{M}$ & 7.07 & 9.03 & $30.0 \mathrm{k}$ & 28526 & 518 & 658 & 1947 \\
\hline 2015 & 14.14 & 7.33 & $8.66 \mathrm{M}$ & 7.47 & 9.45 & $51.4 \mathrm{k}$ & 41974 & 738 & 1216 & 1577 \\
\hline 2016 & 14.08 & 7.40 & $7.92 \mathrm{M}$ & 7.15 & 9.13 & $45.7 \mathrm{k}$ & 39547 & 480 & 1509 & 812 \\
\hline 2017 & 13.57 & 7.49 & $5.79 \mathrm{M}$ & 7.41 & 8.96 & $32.6 \mathrm{k}$ & 21951 & 376 & 3413 & 23625 \\
\hline
\end{tabular}

Note. $F_{H D}$ : The $F$-statistic comparing hailed to dispatched tip percentage (degrees of freedom are 1 and infinity for each main effect and covariate test).

$F_{P}=$ number of passengers; $F_{D}=$ day of the week; $F_{M}=$ month of the year.

$* p<.001$, after Bonferroni correction. 


\section{TAXI TIPPING IN NYC}

were tipped significantly higher than drivers in dispatched cabs.

As one final precaution, we conducted a nonparametric alternative to our original analysis. By converting data to ranks, the Mann-Whitney test is not subject to distributional assumptions like normality and variance homogeneity (Howell, 2010). Once again, the nonparametric analysis confirmed the conclusions from our original analysis, for each of the four years: $2014(z=99.19, p<.001), 2015$ $(z=146.93, p<.001), 2016(z=149.32, p<.001)$, and $2017(z=112.80, p<.001)$. We should point out, however, that, consistent by year, the proportion of variance in tip percentage explained by Trip Type was very small, a mere $R^{2}=.05$ for each of 2014, 2015, and 2016; and $R^{2}=.08$. Conversely, these results showed that $99.2 \%$ to $99.5 \%$ of the differences in tip percentages are explained by variables other than Trip Type.

\section{Discussion}

The present study evaluated whether the reciprocity theory could explain differential tipping percentages as offered to hailed vs. dispatched taxi drivers. We utilized an especially large taxi database from New York City, consisting of both tip percentage and hailed vs. dispatched fares. After controlling for number of passengers and both day and month of travel, our analysis confirmed the hypothesis that patrons in hailed cabs tipped more (double the percentage, $14 \%$ ) than patrons in dispatched cabs (7\%). We grant that the database did not directly measure patrons' perceptions of reciprocity or gratitude, nor could we know the precise mechanism that motivated tipping (viz., need for equity or the driver's intention to help). Yet, we explore those below for future research.

We also address the especially small effect sizes observed in the present study (i.e., $0.5 \%$ of explained variance). Whereas this result is not uncommon in the analysis of especially large datasets (Tabachnick \& Fidell, 2013), we are reminded that other variables are needed to explain differences in tip percentage. It further invites us to consider how statistically significant results may lack practical significance (Cohen, 1988). We have offered the reader several avenues for future research to introduce successful candidates in the understanding of those variables that account for the variability in tip percentage.

The present results augment an already large body of literature in support of reciprocity theory (Gilovich et al., 2019). Indeed, these results align well with those observed in the context of the service industry. Specifically, tips were higher with longer cab rides and enhanced interactions (Aydin \& Acun, 2019), or after receiving a touch or compliment or introduction from waitstaff (Crusco \& Wetzel, 1984; Garrity \& Degelman, 1990; Seiter \& Dutson, 2007), or a candy with the bill (Azar et al., 2015; Rind \& Bordia, 1995, 1996). Similarly, prior research showed patrons who spent more time in the restaurant but incurred a small bill could rebalance the perceived inequity by leaving a larger tip (Lynn et al., 2012). In short, as Regan (1971) noted, when a small favor is done for us, the norm of reciprocity fuels our motivation to right the imbalance. Van Vaerenbergh and Holmqvist (2013) concluded that people do indeed feel the need to balance apparent inequities (receiving something for nothing) in their interpersonal interactions. This may suggest that passengers believe a hailed cab aided them in their time of need (surpassing typical service and garnering a larger tip). Moreover, the taxi service's central dispatch may elect to send a more expensive vehicle on a pre-arranged fare. Conversely, the hailed (and potentially less affluent vehicle) driver might invite a greater tip due to empathy to their financial needs. Future research would also do well to explore in-depth the cognitive processes of customers before, during, and after service from a hailed cab vs. dispatched cab.

Lynn (2016) further explains how the tip amount is influenced by the interaction of occupation and three customer motivations. For instance, patrons may tip by altruistic motives (i.e., helping people who appear to be struggling) for all 21 occupations studied, but in particular among occupations who receive occasional tips like an airport porter, casino dealer, hotel maid, and golf caddie. Alternatively, patrons may tip by duty motives (i.e., compliance with a social norm) chiefly to those in occupations who receive frequent tips like a taxi driver, bartender, hairstylist, and pizza delivery driver. Finally, patrons may tip by reciprocity motives (i.e., a token return for superior service) chiefly among occupations less familiar with tipping like restaurant takeout orders. As expected, altruism motives correlated with neither duty nor reciprocity motives, whereas duty and reciprocity motives were positively related. Whereas it may be argued that duty motives are likely dominant in the taxi industry, we cannot rule out the impact of both altruistic motives (e.g., the driver appears to be struggling financially) or reciprocity motives (e.g., superior service from help with luggage) therein. Future research should explore the role of these motives in the taxi industry (Lynn, 2016).

\section{Limitations and Implications}

Various limitations within the present study warrant mention. To begin, whereas both cash and credit transactions were logged, only tips from credit transactions were recorded. Because credit 


\section{RAYMOND \& CRAMER}

transactions separated fare and tip, we cannot know whether patrons offered a cash tip following a credit payment on the fare only. As such, this could introduce a significant bias in the interpretation of results, since any cash tipping would be logged as null on the credit card. It is feasible that the tipping patterns and behavior of patrons who carry cash can differ from those of credit-card patrons. Those same two groups may be differentially impacted by the social forces that fuel reciprocity. As such, the inability of the database to adequately track cash tips and transactions would necessarily underestimate the overall variability in the cab patrons' tipping patterns.

Furthermore, although the taxi database represented the bulk of taxi operatives in New York City, smaller operations (including Uber and Lyft drivers) were not included; we must conclude that the database, though useful, was not complete. We found the wide disparity in the proportion of taxi fares that were hailed $(99 \%)$ versus dispatched $(1 \%)$ curious. Whereas dispatched fares constituted a modest proportion of the total number of cab fares in New York, the overall number $(162,000)$ remains enormous; so, we remain confident in our conclusions based on analysis of this group. On the one hand, we recognize how the convenience of alternatively recruiting a cab online would necessarily invite private transport services like Uber and Lyft (and lesser known service from Gett, Via, and Juno) that in 2017 overtook New York City cabs as the primary source of cab transport (Bhuiyan, 2018). One would expect an even greater market share to be absorbed by private transport services in future assessments.

We also recognize the differential data loss across the four years $(11 \%$ for 2014 vs. $1-2 \%$ for 2015 2017). Although we cannot know for certain, we hazard to suggest that early data loss (2014) occurred due to the novelty of data collection among cab operators charged with the task of electronic accuracy -likely corrected in later years. Given the comparable results across the four years, we believe that the early data loss in 2014 remains significant but not impactful. Thus, we feel confident that our conclusions can be generalized to the typical tipping behavior of New York City taxi patrons.

The data were collected through an electronic system that recorded strictly factual data (viz., time and date, number of passengers, distance travelled, toll fees, total fare, and tip amount). Other valuable information on passenger gender, age, or ethnic background was not collected. This is especially relevant concerning the interaction between two norms-reciprocity and culture. That is, reciprocity has been found to differ between patrons from individualist nations (e.g., Canada, the United States, and Western Europe) and those from collectivist nations (e.g., Latin America and Southeast Asia). One study by Jung et al. (2014) uncovered reciprocity norm differences between respondents from Japan and the United States. They further showed two cultures differed in their motivation to reciprocate to either friends or strangers-there was no difference in positive reciprocity between friends and strangers for individualist Americans. Still, Japanese collectivists reciprocated more positively when they believed their unknown partner was their friend. Moreover, American participants reciprocated more positively when treated positively, and negatively when treated negatively, whereas Japanese participants displayed consistently neutral responses regardless of treatment. Hence, future research might explore both (a) how the ethnic congruence between patron and driver might decrease tipping (via a similarity hypothesis), whereas incongruence might decrease tipping; and (b) how cultural background interacts with token favors like paying a compliment.

\section{Conclusion}

Our exploratory study is unique in its analysis of differential tipping as a function of hailed vs. dispatched cabs. Within the context of the taxi industry, these results offer empirical support for the reciprocity theory in the psychology of gratuities. It should help inform future drivers on means to garner greater tips upon dispatch, whether through subtle but engaging social interaction rather than more direct compliments and flattery. Future research should step beyond this large dataset and consider smaller experimental designs to address the precise mechanism in reciprocity that motivates enhanced tipping, whether the need for equity or one's intention to help another. These can be addressed either through manipulation of group dynamics (cf. Regan, 1971) or through brief surveys upon cab exit at an airport or theater. In short, either approach would add necessary elements so that we may fully understand the underlying process behind reciprocity in taxi tipping.

\section{References}

Aydin, A. E., \& Acun, Y. (2019). An investigation of tipping behavior as a major component in service economy: The case of taxi tipping. Journal of Behavioral and Experimental Economics, 78, 114120.

Azar, O. H. (2003). The history of tipping - From sixteenth century England to United States in the 1910s. The Journal of Socio-Economics, 33, 753754.

Azar, O. H. (2005). The social norm of tipping: Does it improve social welfare? Journal of Economics, 85, 141-173. 
Azar, O. H. (2007). Do people tip strategically, to improve future service? Theory and evidence. Canadian Journal of Economics, 40, 515-527.

Azar, O. H. (2010). Do people tip because of psychological or strategic motivations? An empirical analysis of restaurant tipping. Applied Economics, 42, 3039-3044.

Azar, O. H., Yosef, S., \& Bar-Eli, M. (2015). Restaurant tipping in a field experiment: How do customers tip when they receive too much change? Journal of Economic Psychology, 50, 13-21.

Becker, C., Bradley, G. T., \& Zantow, K. (2012). The underlying dimensions of tipping behavior: An exploration, confirmation, and predictive model. International Journal of Hospitality Management, $31,247-256$.

Bhuiyan, J. (2018). Ride-hail apps like Uber and Lyft generated 65 percent more rides than taxis did in New York in 2017. Retrieved from https:// www.vox.com/2018/3/15/17126058/uber-lyft-taxis -new-york-city-rides

Cialdini, R. B. (1993). Influence: Science and practice (3rd ed.). New York, NY: Harper Collins.

Cohen, J. (1988). Statistical power analysis for the behavioural sciences (2nd ed.). Hoboken, NJ: Lawrence Erlbaum.

Crusco, A. H., \& Wetzel, C. G. (1984). The Midas Touch: The effects of interpersonal touch on restaurant tipping. Personality and Social Psychology Bulletin, 10, 512-517.

Fehr, E., \& Gächter, S. (2000). Fairness and retaliation: The economics of reciprocity. Journal of Economic Perspectives, 14, 159-181.

Field, A. (2013). Discovering statistics using IBM SPSS statistics. London, United Kingdom: Sage.

Garrity, K., \& Degelman, D. (1990). Effects of server introduction on restaurant tipping. Journal of Applied Social Psychology, 20, 168-172.

Gilovich, T., Keltner, D., Chen, S., \& Nisbett, R. E. (2019). Social psychology (5th ed.). New York, NY: Norton.

Gouldner, A. W. (1960). The norm of reciprocity: A preliminary statement. American Sociological Review, 25, 161-178.

Howell, D. C. (2010). Statistical methods for psychology (7th ed.). Belmont, CA: Wadsworth.

Jung, Y. B., Hall, J., Hong, R. Y., Goh, T., Ong, N., \& Tan, N. (2014). Payback: Effects of relationship and cultural norms on reciprocity. Asian Journal of Social Psychology, 17, 160-172.

Lynn, M. (2016). Motivations for tipping: How they differ across more and less frequently tipped services. Journal of Behavioural and Experimental Economics, 65, 38-48.

Lynn, M., \& Latané, B. (1984). The psychology of restaurant tipping. Journal of Applied Social Psychology, 14, 549-561.
Lynn, M., Jabbour, P., \& Kim, W. G. (2012). Who uses tips as a reward for service and when? An examination of potential moderators of the servicetipping relationship. Journal of Economic Psychology, 33, 90-103.

New York City Taxi and Limousine Commission. (2019). TLC Trip record data. Retrieved from https://www1 nyc.gov/site/tlc/about/tlc-trip-recorddata.page

New York City Taxi \& Limousine Comission. (2020). Taxicab medallion. Retrieved from https:// www1.nyc.gov/site/tlc/businesses/medallionowners-and-agents.page

Payscale. (2019) PayScale's restaurant report: Best and worst cities for food service workers. Retrieved from https://www.payscale.com/data-packages/ restaurant-report/best-and-worst-cities-for-foodservice-workers.

Regan, D. T. (1971). Effects of a favor and liking on compliance. Journal of Experimental Social Psychology, 7, 627-639.

Rind, B., \& Bordia, P. (1995). Effect of server's "Thank You" and personalization on restaurant tipping. Journal of Applied Social Psychology, 25, 745-751.

Rind, B., \& Bordia, P. (1996). Effect on restaurant tipping of male and female servers drawing a happy, smiling face on the backs of customers' checks. Journal of Applied Social Psychology, 26, 218-225.

Rind, B., \& Strohmetz, D. (1999). Effect on restaurant tipping of a helpful message written on the back of customers' checks. Journal of Applied Social Psychology, 29, 139-144.

Segrave, K. (2009). Tipping: An American social history of gratuities. Jefferson, NC: McFarland \& Company.

Seiter, J. S. (2007). Ingratiation and gratuity: The effect of complimenting customers on tipping behavior in restaurants. Journal of Applied Social Psychology, 37, 478-485.

Seiter, J. S., \& Dutson, E. (2007). The effect of compliments on tipping behavior in hairstyling salons. Journal of Applied Social Psychology, 37, 1999-2007.

Strohmetz, D. B., Rind, B., Fisher, R., \& Lynn, M. (2002). Sweetening the till: The use of candy to increase restaurant tipping. Journal of Applied Social Psychology, 32, 300-309.

Tabachnick, B. G., \& Fidell, L. S. (2013). Using multivariate statistics (6th ed.). Toronto, Canada: Pearson.

Tip [Def. 10]. (n.d.). In Merriam-Webster. Retrieved from https://www.merriam-webster.com/ dictionary/tip 
RAYMOND \& CRAMER

Van Vaerenbergh, Y., \& Holmqvist, J. (2013). Speak my language if you want my money. European Journal of Marketing, 47, 1276-1292

Received May 30, 2019

Revision received October 21, 2019 Accepted February 16, 2020 